Presented at the Workshop On Advanced

Accelerator Concepts

Port Jefferson, NY, June 15-19, 1992

BNL- -48004

DE93 001964

\title{
PHOTOEMISSION FROM Ag, Cu, AND CsI
}

\author{
T. Srinivasan-Rao, J. Fischer and T. Tsang \\ Brookhaven National Laboratory, Upton, NY 11973
}

JUNE 1992

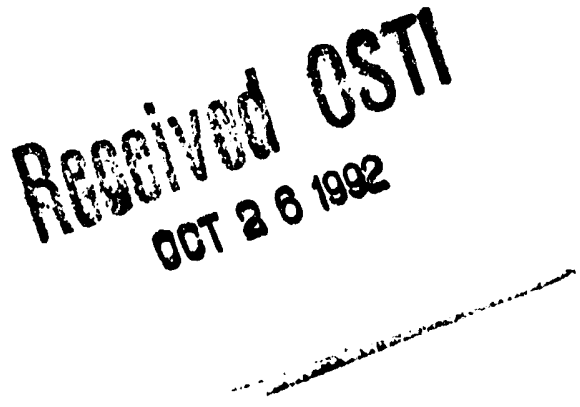

DISCLAIMER

\begin{abstract}
This report was prepared as an account of work sponsored by an agency of the United States Government. Neither the United States Government nor any agency thereof, nor any of their employees, makes any warranty, express or implied, or assumes any legal liability or responsibility for the accuracy, completeness, or usefulness of any information, apparatus, product, or process disclosed, or represents that its use would not infringe privately owned rights. Reference herein to any specific commercial product, process, or service by trade name, trademark, manufacturer, or otherwise does not necessarily constitute or imply its endorsement, recommendation, or favoring by the United States Goyernment or any agency thereof. The views and opinions of authors expressed herein do not necessarily state or reflect those of the United States Government or any agency thereof.
\end{abstract}

*This research was supported by the U. S. Department of Energy: MASTER Contract No. DE-AC02-76CH00016. 
PHOTOEMISSION FROM Ag, $\mathrm{Cu}$, AND CsI

T. SRINIVASAN-RAO, J, FISCHER, T. TSANG

BROOKHAVEN NATIONAL LABORATORY, UPTON, N.Y. 11973

ABSTRACT

Photoemission characteristics of three different cathodes, CsI, $\mathrm{Ag}$ film and $\mathrm{Cu}$ were investigated. CsI, upon irradiation by $213 \mathrm{~nm}, 10 \mathrm{ps}$ laser pulse yields a quantum efficiency of $4 \%$ at $0.2 \mu \mathrm{J}$ input energy. The saturation mechanism observed at higher input energies require further investigation. Ag film, upon irradiation by $630 \mathrm{~nm}, 300 \mathrm{fs}$ laser emit prompt photoelectrons after absorbing 2 photons. There was no evidence of optical damage of the film up to $10^{11} \mathrm{w} / \mathrm{cm}^{2}$. At low intensities, photoemission from $C u$ is a simple $\nu-e^{-}$interaction, the nonlinearity of the process depending strongly on trace impurities. At higher intensities, there appears to be a change in the emission mechanism.

\section{INTRODUCTION :}

In recent years there has been considerable interest ${ }^{1-3}$ in using photoemission technique to generate high quality, low emittance and high brightness electron beams for high energy colliders and short wavelength free electron lasers. These applications call for a high quantum efficiency $(-1 \%)$, rugged, long life-time photocathode material that is capable of operating in $10^{-8}$ Torr pressure, using a simple, short pulse laser. So far no single photocathode material has met all these requirements simultaneously. Our investigation of CsI was motivated by its capability to meet most of the above requirements. There are also other applications such as the switched power high brightness gun ${ }^{4}$ and positron production by $e^{-}-\boldsymbol{\gamma}$ and $\boldsymbol{\gamma}-\boldsymbol{\gamma}$ interaction ${ }^{5}$ that require electron bunches of subpicosecond duration. Our investigation of $\mathrm{Cu}$ and $\mathrm{Ag}$ using femtosecond laser pulses were motivated by these applications. In the subsequent sections the results of experiments with CsI irradiated by $266 \mathrm{~nm}$ and $213 \mathrm{~nm}$ laser pulse of - 10 ps duration and $\mathrm{Ag}$ film and $\mathrm{Cu}$ irradiated with $630 \mathrm{~nm}$ laser pulse of $300 \mathrm{fs}$ are discussed.

\section{MEASUREMENTS ON CSI USING PS LASER PULSES}

\section{EXPERIMENTAL ARRANGEMENT:}

Preparation of the CsI photocathocie was as follows. Bulk CsI was vapor deposited on diamond turned $\mathrm{Cu}$ to a thickness of $8000 \AA$, transported in an evacuated container and the electrodes were assembled together with minimum exposure to air. The anode was a hollow cylinder of $6 \mathrm{~mm}$ inner diameter, the opening nearest to the cathode covered with a copper mesh of 70 lines/inch. The electrodes, spaced apart by $1 \mathrm{~mm}$, were then set in the vacuum cell and baked at $100-140^{\circ} \mathrm{C}$ overnight. 
The anode can be biased up to a voltage of $10 \mathrm{kV}$, but normally maintained between 2 to $4 \mathrm{kV}$ to limit the possibility of high voltage breakdown in vacuun.

The laser used to irradiate the CsI was an actively and passively mode-locked Nd-YAG laser operating at $1.06 \mu \mathrm{m}$, with $-25 \mathrm{~mJ}$ energy in 25 ps duration. Radiation at $0.266 \mu \mathrm{m}$ and $0.213 \mu \mathrm{m}$ were obtained using different nonlirear crystals. It was possible to obtain up to $1.5 \mathrm{~mJ}$ in $12 \mathrm{ps}$ and $100 \mu \mathrm{J}$ in $-10 \mathrm{ps}$ at wavelengths $0.266 \mu \mathrm{m}$ and $0.213 \mu \mathrm{m}$, respectively. The two wavelengths were separated using a fused silica prism and only one of the wavelengths was directed to illuminate the cathode. A small percent of the laser beam was deflected to a calibrated photodiode to monitor the energy of the irradiating beam. The photoemission signal was extracted from the cathode and displayed on the oscilloscope after passing it through a charge sensitive preamplifier and a shaping amplifier when needed. Fig. 1 illustrates the experimental lay-out.

MEASUREMENTS WITH $0.266 \mu \mathrm{m}$ RADIATION:

The dependence of the charge on the input laser energy was determined by varying the laser energy and observing the corresponding charge emitted and the results are displayed in Fig 2. The slope of this logarithmic plot, an indicator of the number of photons involved in the process, indicates that the photoemission at this wavelength is a single photon process and the quantum efficiency is $~ 2 \times 10^{-6}$. Considering the facts that the absorption coefficient of CsI at this wavelength is $-1.7 \mathrm{~cm}^{-1},{ }^{6}$ the thickness of the CsI in our sample is $8000 \AA$ and the substrate is copper whose quantum efficiency at this wavelength is very close to this measured value, the observed photoelectrons could have originated from the substrate and not from CsI. However, this fact needs to be verified by varying both the thickness and the material of the substrate. The capability of these electrons to tunnel through the CsI layer also needs to be investigated.

MEASUREMENTS WITH $0.213 \mu \mathrm{m}$ RADIATION:

Fig. 2 also illustrates the intensity dependence of the photoelectrons at $0.213 \mu \mathrm{m}$ radiation. The slope of the plot indicates that photoemission at this wavelength requires two photons. The quantum efficiency at $0.2 \mu \mathrm{J}$ incident laser energy is $-4 \%$. However, as the laser energy approaches $-1 \mu \mathrm{J}$, the electron yield appears to saturate and become independent of the incident laser energy. This saturation is unlikely due to space charge effects as evidenced by the voltage dependence data. Fig. 7. Similar effect has been observed on cesium activated GaAs ${ }^{7}$ and has been attributed to the formation of plasma and subsequent modification of the work function. The validity of this explanation for CsI is currently under investigation. Measurements at both wavelengths agree with results from other laboratories ${ }^{8}$.

MEASUREMENTS WITH SILVER USING FEMTOSECOND LASER PULSES: 
The preparation of the silver cathode was similar to that of CsI. 3100 A thick silver was evaporated on a diamond turned $\mathrm{Cu}$ mirror. The cathode was transported in an evacuated cell and the electrodes were assembled and mounted in the vacuum cell. As before, the anode was a hollow cylinder, but with the opening nearest to the cathode covered by a 40 lines/inch nickel mesh. The electrode gap was $1 \mathrm{~mm}$.

The laser used in these experiments was an amplified colliding pulse mode-locked (CPM) laser. The output characteristics of the laser are as follows: wavelength was $630 \mathrm{~nm}$, energy was $1 \mu \mathrm{J}$, pulse duration was $300 \mathrm{fs}$, focused spot size, FWHM, on the cathode was $100 \times 70 \mu \mathrm{m}^{2}$.

Figs. 3 and 4 illustrate the intensity and the voltage dependence of the electron emission respectively. As can be seen from the intenisity dependence data, photoelectric cmission at this wavelength is a two photon process. The data taken with the unamplified CPM and the amplified CPM mesh smoothly without any normalization indicating the absence of any other nonlinear mechanism.

The maximum current density measured with this cathode was $4000 \mathrm{~A} / \mathrm{cm}^{2}$. The maximum charge extracted was limited by the available laser energy. The measured quantum efficiency was low, however, it has been proven ${ }^{9}$ that at grazing incidence, the presence of the electric field of the ( $p$ - polarized) laser enhances the quantum efficiency to a level comparable to that of a single photon process, which is $-10^{-5}$ electrons per incident $2 \mathrm{eV}$ photon for $\mathrm{Ag}$.

The slope of the voltage dependence curve (Fig. 4) is high, implying strong modification of the work function due to Schottky effect. The slopes of these curves for various input laser intensities scale with the input intensity linearly, supporting the evidence for the two photon process.

The pulse duration of the electron bunch was measured using the autocorrelation technique. The laser beam was split into two equal halves, passed through delaying optics, and recombined on the target. One beam was delayed with respect to the other by translating its delaying optics with a fine stepper motor. The electron signal was measured as a function of the delay and displayed in Fig. 5. The autocorrelation trace of the laser pulse is also displayed along side for reference. As can be seen from Fig. 5 the electron pulse duration is comparable to the laser pulse duration. Due to the low signal to noise ratio encountered in these measurements, it is not possible to verify the origin of the slight broadening of the electron pulse length. The silver film was not optically damaged even at intensities of $10^{11} \mathrm{~W} / \mathrm{cm}^{2}$.

\section{MEASUREMENTS WITH COPPER USING FEMTOSECOND LASER PULSES:}

The experimental arrangement for these measurements were similar to that for silver. Fig. 6 illustrates the intensity dependence of the photoemitted electrons. Experiments with two different copper samples indicate that nonliniearity of photoemission from copper under visible radiation is significantly affected by trace embedded and surface impurities. The presence of $\mathrm{CuCl}$ could provide a long lived intermediate state ${ }^{10}$ and cause a 3 photon process to appear as a 2 
photon process and the presence of trace amounts of Si could change the process from two photon to a single photon process. At low laser intensities, the photoemission requires two photons for the sample without trace amounts of $\mathrm{Si}$ and one photon for the sample with traces of Si. For a number of Cu samples investigated, as the laser intensity increased beyond $10^{10} \mathrm{~W} / \mathrm{cm}^{2}$, the number of photoelectrons increased abruptly by thousandfold. The sharp onset of this behavior and the amplitude fluctuation of the laser energy precluded using autocorrelation technique for pulse duration measurements. However, the lower limit on the pulse duration can be estimated. For $\mathrm{Ag}$, the onset of space charge limited photoemission was at $100 \mathrm{fc}$ and the corresponding measured pulse duration was $\approx 250 \mathrm{fs}$. For copper, even at a charge of $100 \mathrm{pc}$, the space charge limit is not reached for similar electrode geometry. Hence, the pulse duration of the electrons have to be larger than $250 \mathrm{ps}$. The time resolution of our measurement system is $1 \mathrm{~ns}$ and the oscilloscope traces did not indicate pulses longer than 1 ns. Hence the pulse duration of this bunch must lie between .25 and 1 ns, much longer than the laser pulse duration. Similar behavior from copper with longer pulse duration has been observed previously 11 and attributed to the formation and expansion of plasma from the copper surface. The short pulse behavior is being analyzed at present.

\section{CONCLUSIONS}

Photoemission from CsI indicates that quantum efficiencies exceeding $1 \%$ could be obtained from rugged materials. The operating wavelength, although high, is not too difficult to achieve. Since CsI is an irsulator, the number of available electrons may not be as high as a metal cathode. Hence the capability of CsI to yield short bunch electron charges $\gg 1 \mathrm{nC}$ has to be investigated in detail. Photoemission measurements on $\mathrm{Ag}$ and $\mathrm{Cu}$ using femtosecond laser pulses indicate that high current electron pulses in short bursts are achievable with reasonable quantum efficiencs. However, further studies, such as effects of electromagnetic fields associated with the laser, non-uniform heating of the electron, plasma production, and emittance characteristics are required before adopting it in other applications.

\section{REFERENCES}

1. J. S. Fraser, R. L. Sheffield, E. R. Gray, P. M. Giles, R. W. Springer, and V. A. Loebs, Proceedings of the 1987 Particle Accelerator Conference, Washington, D.C., 1987, P. 1705

2. K. Batchelor, H. Kirk, J. Sheehan, M. Woodle, and K. McDonald, Proceedings of the European Accelerator Conference, Rome, Italy, 1988, P. 954

3. J. Madson, CERN, Private Communication

4. R. B. Palmer, Proceedings of the Switched Power Workshop, Shelter Island, U. S. A., 1988, BNL 52211, p. 263

5. R. B. Palmer, Presented at this Workshop 
6. P. Avakian and A. Smakula, Phys.Rev. 120, 2007, (1960)

7. Max Zolotorev, SLAC, Private Communication

8. G. Suburlucq, CERN, Private Communication

9. J. P. Girardeau-Montaut, C. Girardeau-Montaut, S. D. Moustaizis and C. Fotakis, Submitted for publication in Phys. Rev. Lett.

10. W. F. Krolikowski, Ph. D. Thesis, Stanford University, 1967, p. 231

11. X. J. Wang, T. Tsang, H. Kirk, T. Srinivasan-Rao, J. Fischer, K. Batchelor, P. Russell, and R. C. Fernow, J. Appl. Phys., 72, 888, (1992)

\section{FIGURE CAPTIONS}

1. Experimental arrangement.

2. Intensity dependence of photoelectrons from $8000 \dot{A}$ thick CsI on diamond turned $\mathrm{Cu}$. The bias voltage was $3.5 \mathrm{kV}$ across $1 \mathrm{~mm}$ gap. o: laser wavelength is $266 \mathrm{~nm}$ and spot size is $3 \mathrm{~mm}$ diameter. $\Delta$ : laser wavelength is $213 \mathrm{~nm}$ and the spot size is elliptical with major and minor axes 2.5 and $2 \mathrm{~mm}$ respectively.

3. Intensity dependence of photoelectrons from $3100 \AA$ thick Ag on diamond turned $\mathrm{Cu}$. 0 : are using unamplified CPM of pulse duration $100 \mathrm{fs} \Delta$ : are with amplified CPM of pulse duration 300 fs .

4. Applied field dependence of photoelectrons from $3100 \AA$ thick $\mathrm{Ag}$ on diamond turned $C u$ with laser energy as a parameter. $m$ is the slope of the line and the ratios listed are $\mathrm{m}_{1} / \mathrm{m}_{2}$.

5. Autocorrelation signals of $(\Delta)$ electrons and $(+)$ laser. The real width is autocorrelation width $/ \sqrt{ } 2$ for a Gaussian profile.

6. Intensity dependence of photoelectrons from diamond turned $\mathrm{Cu}$ cathode. The bias voltage was $2.5 \mathrm{kV}$ across $2.75 \mathrm{~mm}$ gap. The laser pulse duration was $250 \mathrm{fs}$ and the focal spot size was 70 $\mathrm{x} 100 \mu \mathrm{m}^{2}$ FWHM. 


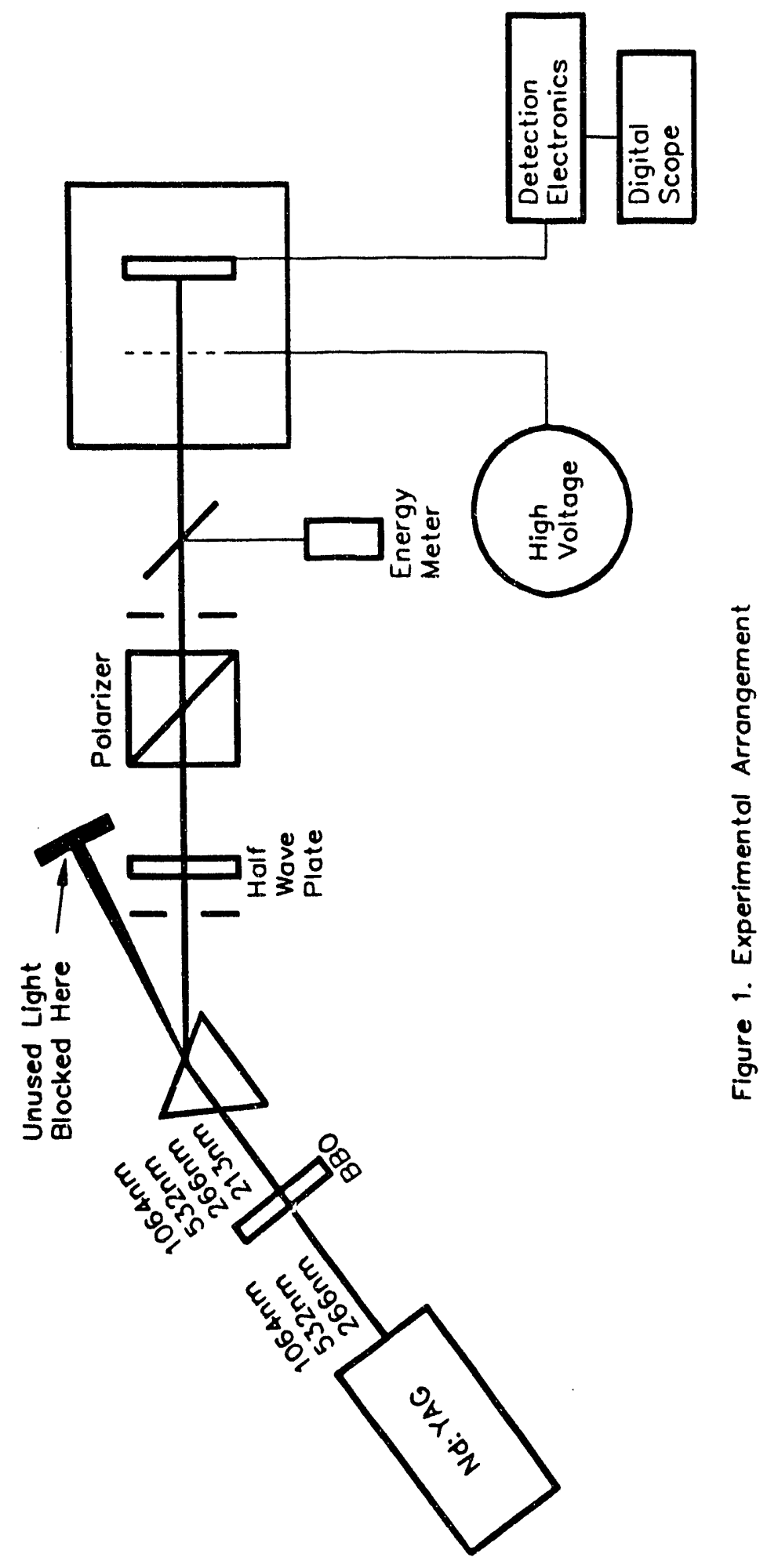




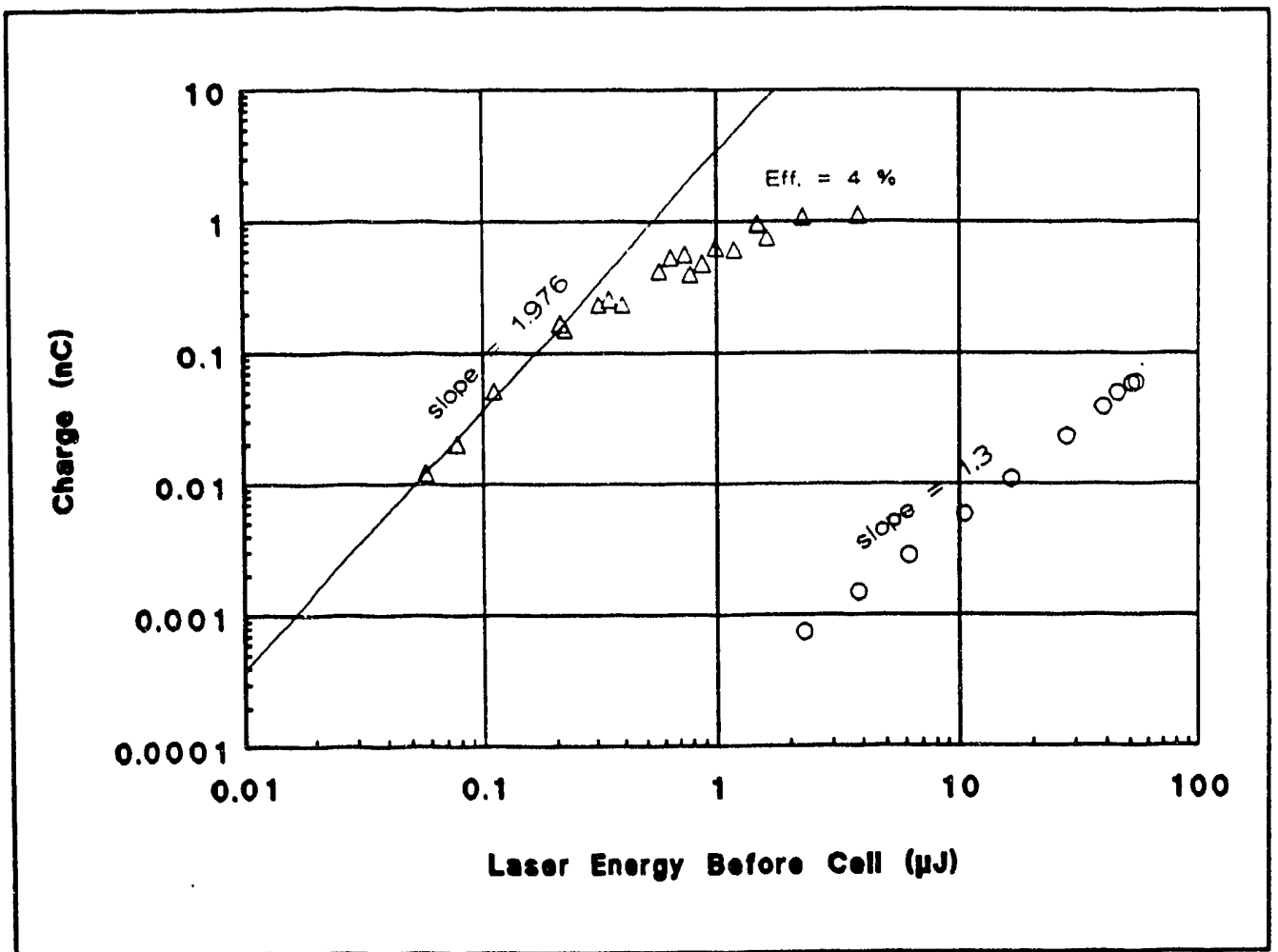

Figure 2. Intensity dependence of photoelectrons from $8000 \AA$ thick CsI on diamond tumed $\mathrm{Cu}$. The bias voltage was $3.5 \mathrm{kV}$ across $1 \mathrm{~mm}$ gap. $O$ : laser wavelength is $266 \mathrm{~nm}$ and spot size is $3 \mathrm{~mm}$ diameter. $\Delta:$ laser wavelength is $213 \mathrm{~nm}$ and the sfoi size is elliptical with major and minor axes 2.5 and $2 \mathrm{~mm}$ respectively. 


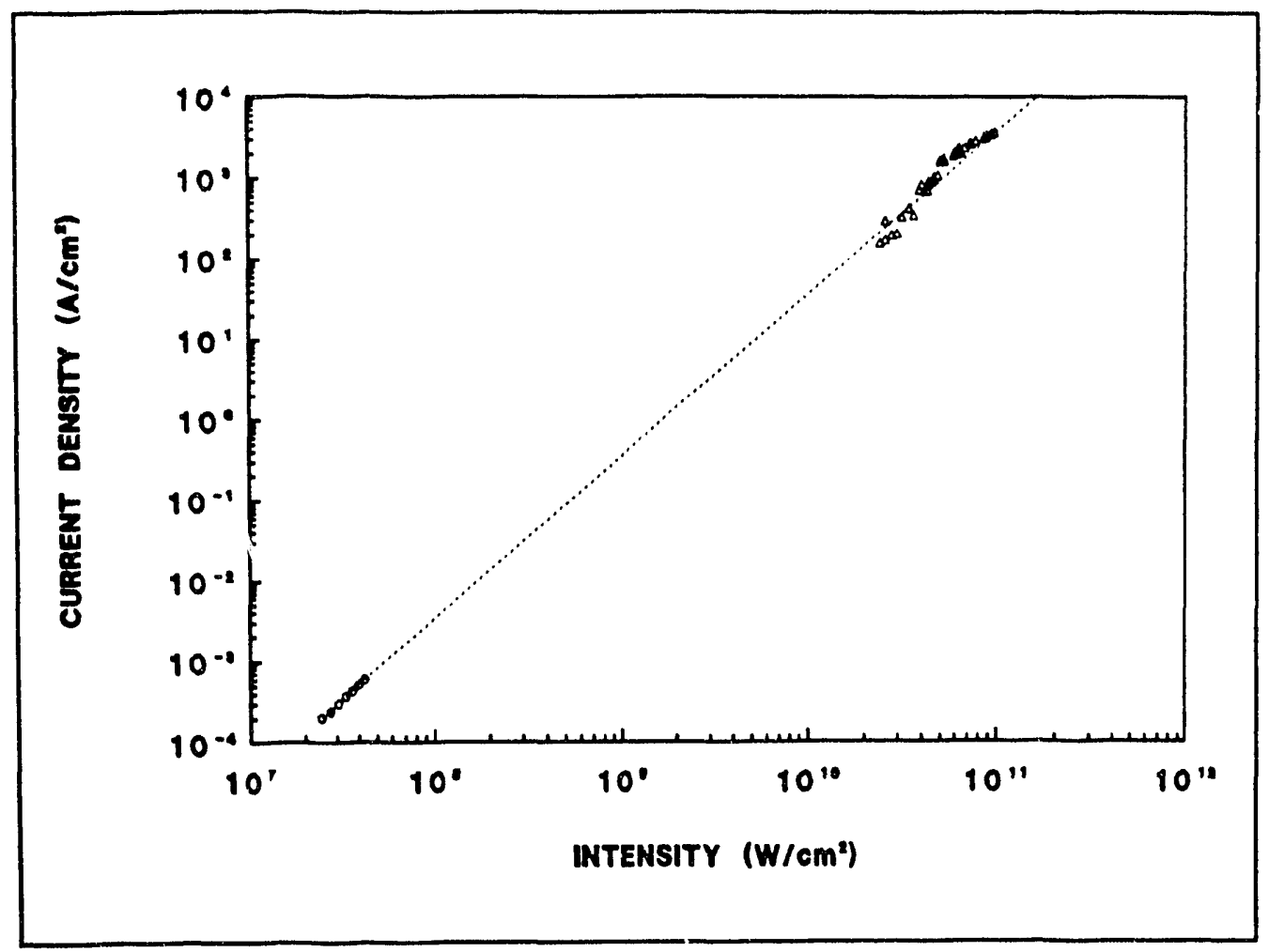

Figure 3. Intensity dependence of photoelectrons from $3100 \AA$ thick $\mathrm{Ag}$ on diamond turned $\mathrm{Cu}$.

O:unamplified CPM laser of pulse duration $100 \mathrm{fs}$

$\Delta$ :amplified CPM laser of pulse duration $300 \mathrm{fs}$ 


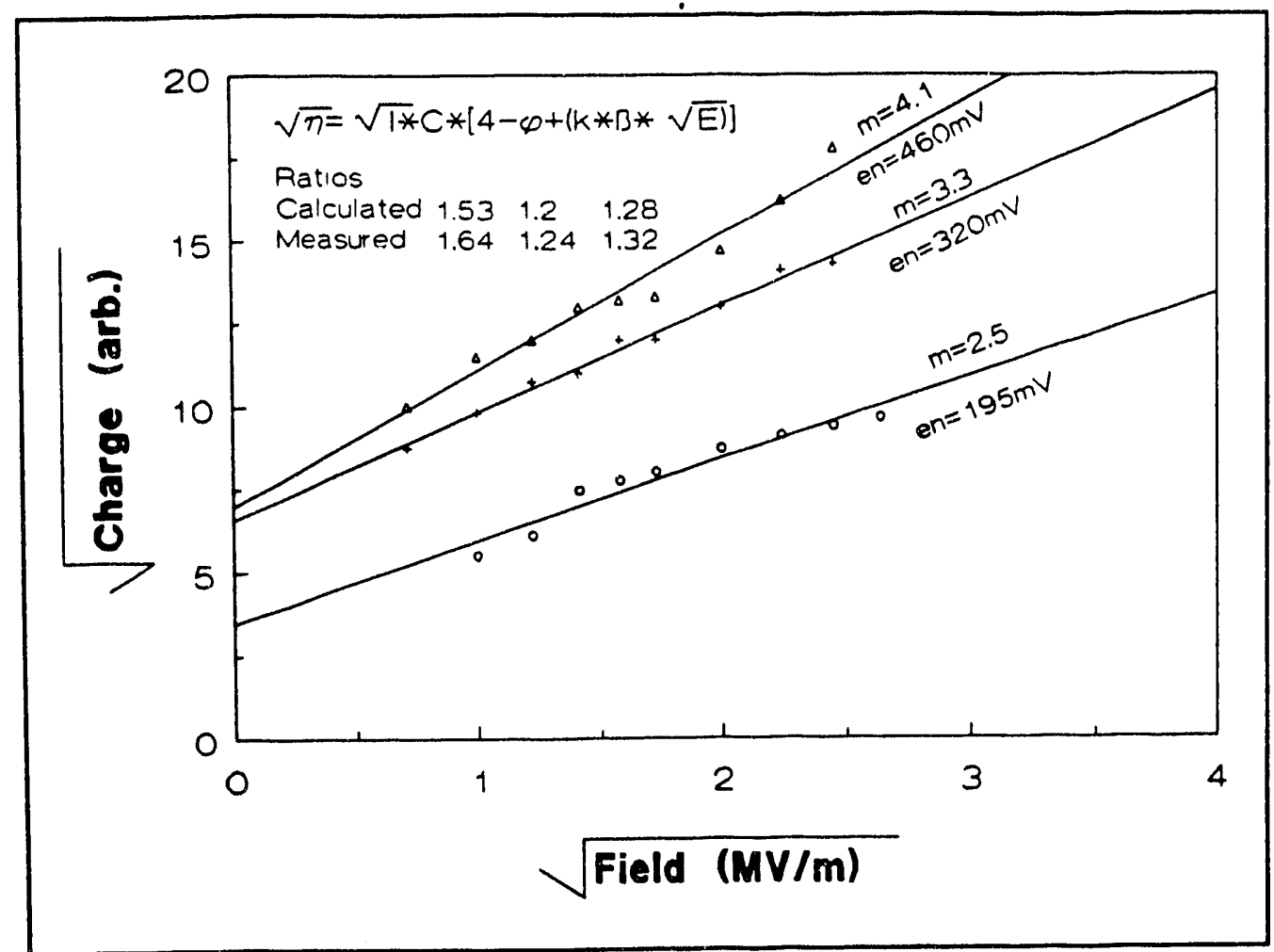

Figure 4. Applied field dependence of photoelectrons from $3100 \AA$ thick $\mathrm{Ag}$ on diamond humed $\mathrm{Cu}$ with laser energy as a parameter. $\mathrm{m}$ is the slope of the line and the ratios listed are $\mathrm{m}_{1} / \mathrm{m}_{2}$. 

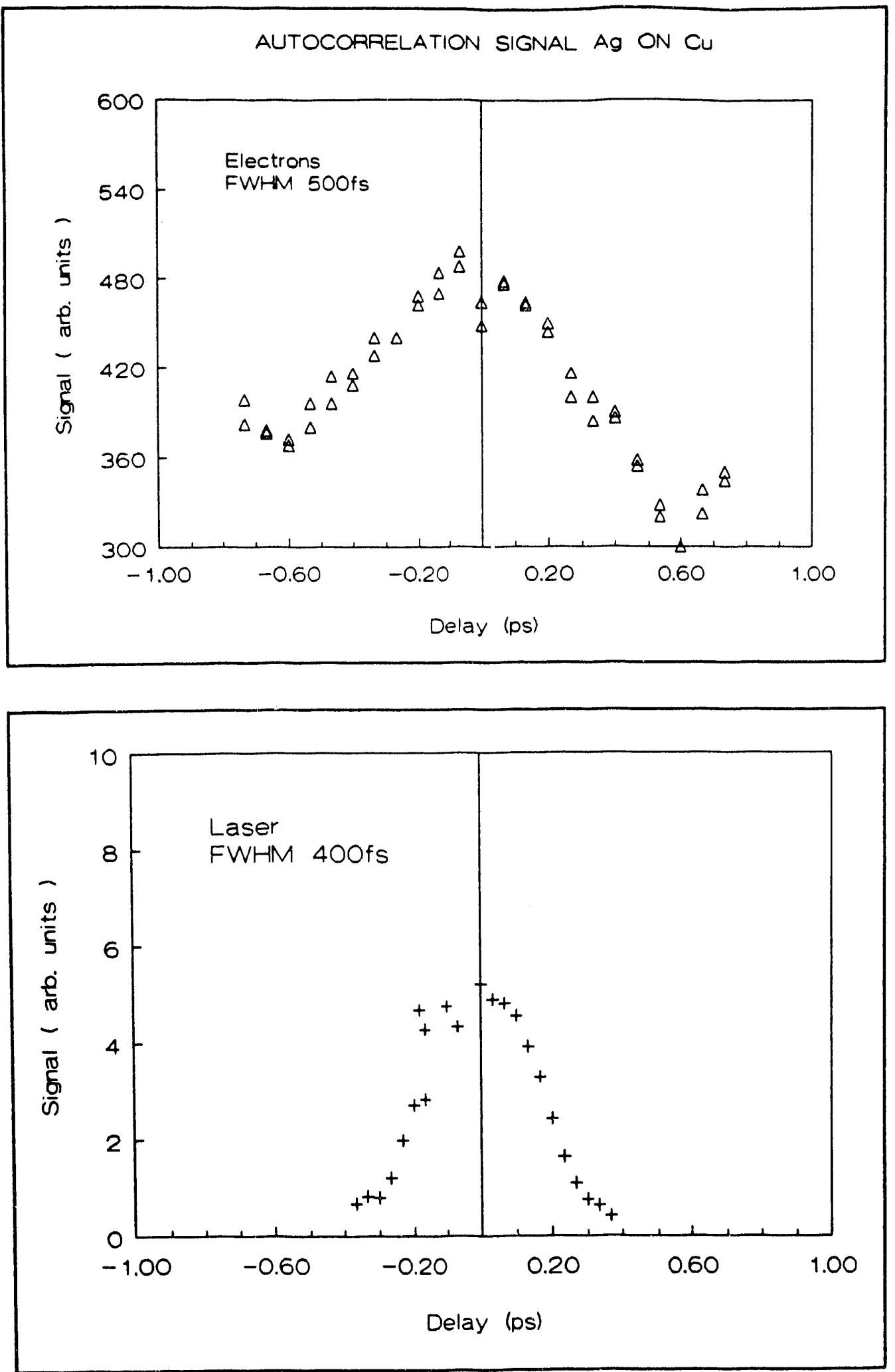

Figure 5. Autocorrelation signals of $(\Delta)$ electrons and $(+)$ laser. 


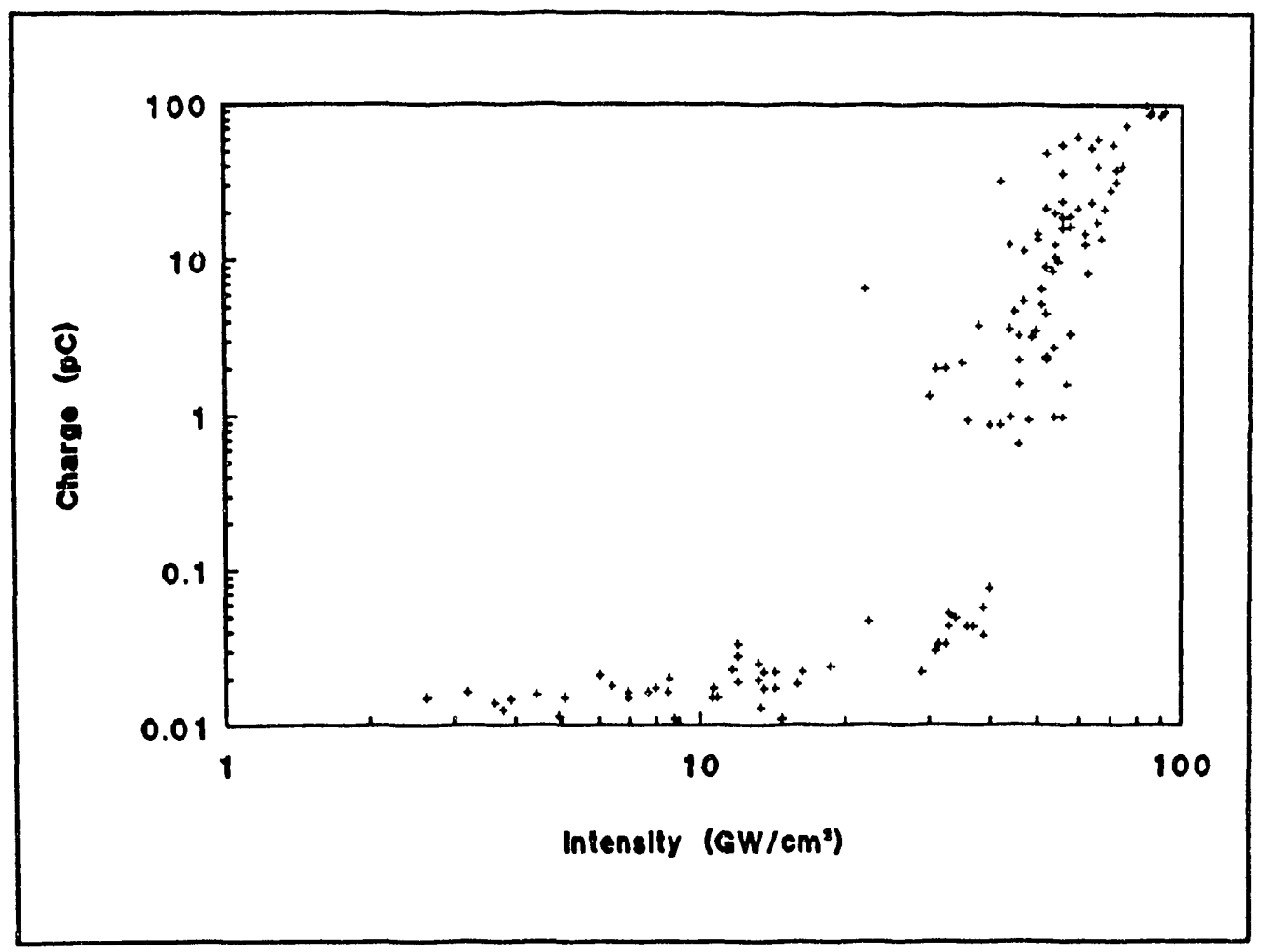

Figure 6. Intensity dependence of photoelectrons from diamond turned $\mathrm{Cu}$ cathode. The bias voltage was $2.5 \mathrm{kV}$ across $2.75 \mathrm{~mm}$ gap. The laser pulse duration was 250 fs and the focal spot size was $70 \times 100$ $\mu \mathrm{m}^{2}$ FWHM. 

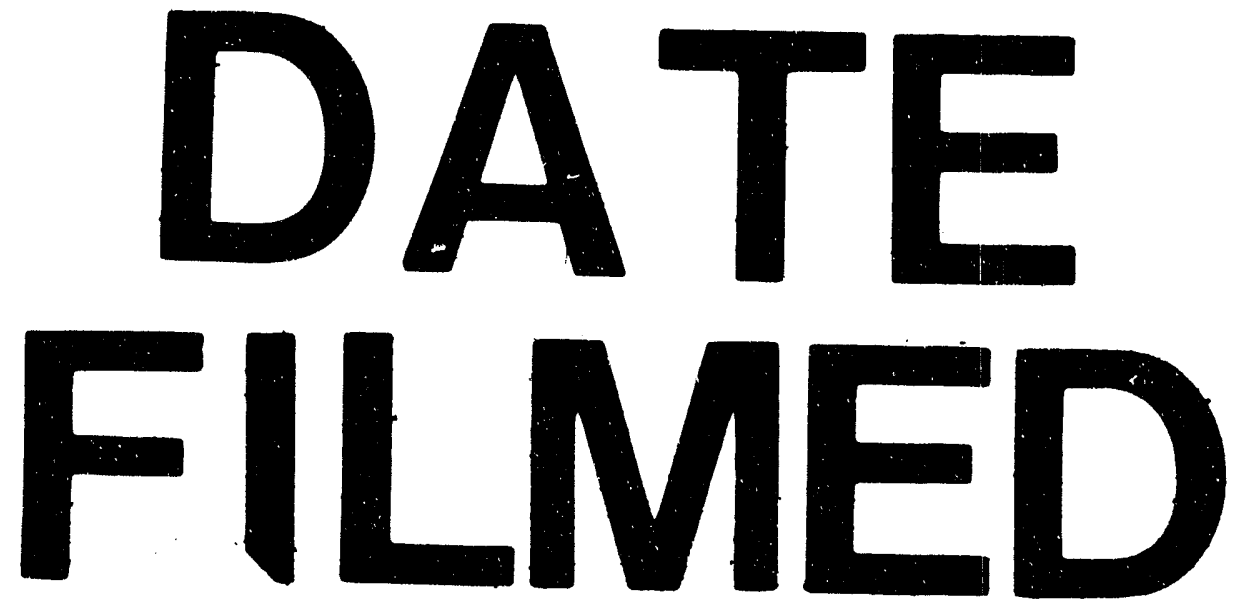

$\cdots$

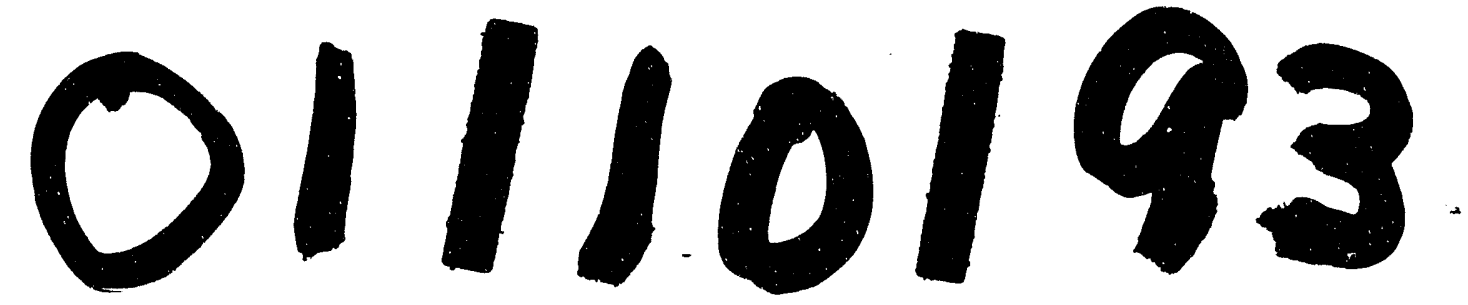




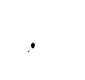

